\title{
A New FEM Approach for the Determination of Fracture Parameters in Polymethyl-metacrylate PMMA
}

\author{
Khelil F. ${ }^{1, *}$, Belhouari M. ${ }^{1}$, Aour B. ${ }^{2}$, Benhamena A. ${ }^{3}$, Benaoum F. ${ }^{2}$ \\ ${ }^{1}$ Department of Mechanical Engineering, University of Sidi Bel Abbes, Algeria \\ ${ }^{2}$ Laboratory of Applied Biomechanics and Biomaterials, Ecole Nationale Polytechnique d'Oran, Algeria \\ ${ }^{3}$ Laboratoire LPQ3M, University of Mascara, Algeria
}

Copyright (C) 2015 by authors, all rights reserved. Authors agree that this article remains permanently open access under the terms of the Creative Commons Attribution License 4.0 International License

\begin{abstract}
The experimental results from the blocks loading fatigue tests are compared with the predictions using the proposed model and Miner's rule. Estimated and experimental results are found to exhibit good agreement. The evaluation technique of the $\mathrm{K}_{\mathrm{I}}$ stress intensity factors (SIF) by a numerical investigation using line strain method is developed. The main purpose of this research is to estimate experimental results of fracture loads from polymethyl-metacrylate (PMMA) specimens (fully finite plates). Stress intensity factor equation calculation is derived from the Williams stress asymptotic expansion. Computed values using finite element analysis of stress intensity factors are compared with the experimental and theoretical results. A good agreement is observed between the present approach and experimental data. It is shown that, in the case of a through-plate crack, the stress intensity factor can be measured with a good accuracy using the proposed method.
\end{abstract}

Keywords Finite Elements, Strain Gage Method, $\mathrm{K}_{\mathrm{I}}$, PMMA, Edge Crack

\section{Introduction}

The measurement of the stress intensity factor with strain gages was first suggested by Irwin [1] in 1957. Due to the local yielding effect at the crack vicinity, little progress has been made in implementing Irwin's suggestion. A valid strain gage technique for measuring stress intensity factor $\mathrm{K}_{\mathrm{I}}$ was first presented by Dally and Sanford [2]. In this method, a valid region was specified for locating the gages to get rid of the elastic-plastic crack-tip state caused by local yielding in the innermost region close to the crack tip. The error caused by strain gradient was minimized by placing the strain gages sufficiently far from the crack tip. An extended over-deterministic approach was proposed by Berger and Dally [3] to improve the accuracy significantly. Itoh et al. [4] measured the stress intensity factors of mixed mode problems by using a specified strain gage pattern. Moreover, different strain gage approaches were introduced by Shukla et al. [5] and Dally and Sanford [6] to measure the variation of stress intensity factor of a propagating crack.

It has long been acknowledged that in plates of finite thickness the stress field near the crack tip is three-dimensional in nature. From the finite element results of Levy et al. [7], Nakamura and Parks [8] and the experimental results of Rosaki s and Ravi-Chandar [9], it has been shown that the local yielding effect is only significant within a radial distance about one-half thickness from the crack tip. For the rest of the area, the plane stress condition is expected to dominate.

The choise of the position and orientation of the point $\mathrm{P}$ for the calculation of $\mathrm{K}_{\mathrm{I}}$ are studied by using virtual gages with two orientation angle $(\Theta, \alpha)$ see fig (1) when considering a line segment in a strain field near the crack tip. A different load and geometry of specimen are also employed to visualize the geometry effect on the evaluated stress intensity factors.

In this work, we investigate the feasibility of the numerical determination of accurate opening mode of stress intensity factors using the Dally-Sanford method [2] for the cracked polymethyl-methacrylate (PMMA) specimens. In this procedure, gages can be placed at low strain gradient zones. In contrast with Dally and Sanford [2]; Wei and Zhao [13]; Kuang and Chen [14] and jogdand [16], our work attempts to measure accurately the SIF using relative large strain points method under monotonic increasing loads in fully finite edge-cracked plates subject. To validate the proposed method for the determination of SIF's, we compare our computer-calculated values obtained using Abaqus finite-element software with experimental results of Swamy et al. [9].

\section{Basic Theory and Mathematical Formulation of the Model}

The area adjacent to the crack tip was divided into three regions. Region I very near the crack tip is invalid because of 
three-dimensional effects. Region III far from the crack tip is invalid because the truncated series solution does not adequately describe the strain field. Region II located between regions I and III is a valid area where the truncated-series solution represents the strain field to a specified accuracy. The size and shape of region II is presented for the compact-tension geometry. Region II was subdivided into regions IIa and IIb. Region IIb was discarded because the strains in this area are too low for accurate measurement.

Dally and Sanford [2] adopted an approach to three parameters who assumed that the deformation field in region II can be represented with sufficient accuracy by the three terms of the William's series [16]. The deformation field in this region for a state of plane stress is then written in the following form Sanford [7]:

$$
\begin{gathered}
E \varepsilon_{x x}=A_{0} r^{-1 / 2} \cos (\theta / 2)[(1-v)- \\
-(1+v) \sin (\theta / 2) \sin (3 \theta / 2)] \\
+2 B_{0}+A_{1} r^{1 / 2} \cos (\theta / 2)[(1-v)+ \\
\left.+(1+v) \sin ^{2}(\theta / 2)\right] \\
E \varepsilon_{y y}=A_{0} r^{-1 / 2} \cos (\theta / 2)[(1-v)+ \\
+(1+v) \sin (\theta / 2) \sin (3 \theta / 2)] \\
-2 v B_{0}+A_{1} r^{1 / 2} \cos (\theta / 2)[(1-v)- \\
\left.-(1+v) \sin ^{2}(\theta / 2)\right] \\
\quad \mu \gamma_{x y}=A_{0} r^{-1 / 2} \sin \theta \cos (3 \theta / 2)- \\
-A_{1} r^{1 / 2} \sin (\theta / 2) \cos (\theta / 2)^{2}
\end{gathered}
$$

Where $\mathrm{A}_{0}, \mathrm{~A}_{1}$ and $\mathrm{B}_{0}$ are unknown coefficients which can be determined by using the specimen geometry and boundary conditions. Using the definition of $\mathrm{K}_{\mathrm{I}}$, one can easily show that it is related to $\mathrm{A}_{0}$ by [2-11]: $K_{I}=\sqrt{2 \pi} A_{0}$

One virtual gage is sufficient to evaluate $\mathrm{A}_{0}$ (where $\mathrm{K}_{\mathrm{I}}$ ) by placing and orienting the strain gage as described in figure(1).

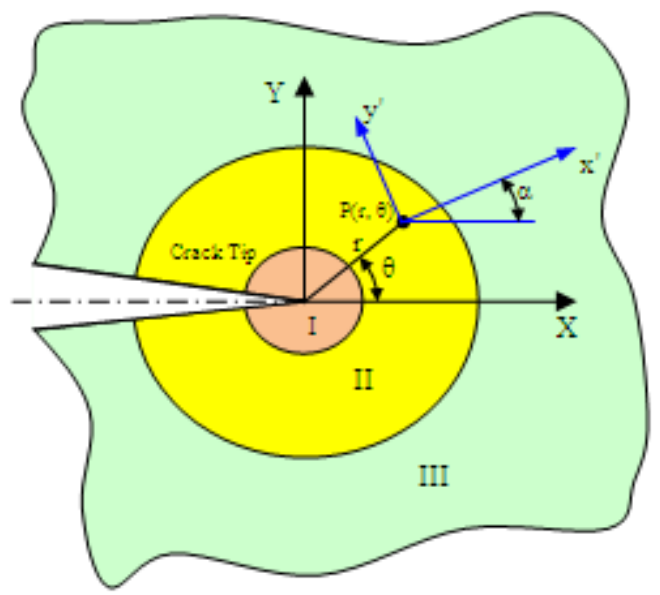

Figure 1. Schematic illustration of the three regions associated with the strain points location and orientation at the crack tip.

$$
\begin{gathered}
2 \mu \varepsilon_{x^{\prime} x^{\prime}}=A_{0} r^{-1 / 2}[k \cos (\theta / 2)-(1 / 2) \sin (\theta / 2) \sin (3 \theta / 2) \\
\cos (2 \alpha)]+(1 / 2) \sin \theta \cos (3 \theta / 2) \sin (2 \alpha)]+ \\
+B_{0}(k+\cos 2 \alpha)+A_{1} r^{1 / 2} \cos (\theta / 2)[k+ \\
\left.+\sin ^{2}(\theta / 2) \cos (2 \alpha)-(1 / 2) \sin \theta \sin 2 \alpha\right]+ \\
\left.+B_{1}(k+\cos 2 \alpha) \cos \theta-2 \sin \theta \sin 2 \alpha\right] \\
k=-\frac{1-v}{1+v}
\end{gathered}
$$

$\mathrm{B}_{0}$ the term coefficient of equation (3) can be removed by selecting the angle $\alpha$, so that

$$
\cos 2 \alpha=-k=-\frac{1-v}{1+v}
$$

The coefficient $A_{1}$, can also be made zero by replacing the angle value of $\alpha$ by:

$$
\tan (\theta / 2)=-\cot 2 \alpha
$$

The strain $\varepsilon_{x^{\prime} x^{\prime}}$ is given by:

$$
\begin{aligned}
2 \mu \varepsilon_{x^{\prime} x^{\prime}}= & \frac{K_{I}}{\sqrt{2 \pi r}}\left(k \cos \frac{\theta}{2}-\sin \theta / 2 \sin 3 \frac{\theta}{2} \cos 2 \alpha\right. \\
& \left.+\frac{1}{2} \sin \theta \cos 3 \frac{\theta}{2} \sin 2 \alpha\right)
\end{aligned}
$$

The angles $\alpha$ and $\theta$ depend only on the Poisson's ratio of the material. The location of the radius rp strain gauge is chosen taking into account the effects of strain gradient [1].

\section{Numerical Procedures}

\subsection{Material Properties}

Specimens are made of polymer PMMA (plexiglass sheet) (Fig. 2a). The mechanical properties are: Young's modulus $\mathrm{E}=2300 \mathrm{MPa}$, Poisson's ratio is $0.37, \mathrm{~K}_{\mathrm{IC}}=0.9-1.4 \mathrm{MPam}^{0.5}$ and $\mathrm{G}_{\mathrm{Ic}}=0.3-0.4 \mathrm{~kJ} / \mathrm{m}^{2}$.

\subsection{Finite Element Model}

Due to symmetry only half of the plate was taken into account in the analysis (Fig. 2b). Isoparametric triangular quadratic elements (T6) have been used at the singular point. Figure 3 shows a typical mesh used for determining the standard SIF. These meshes were used for all values of a/W and $\mathrm{h} / \mathrm{W}$. When the mesh was refined significant improvements were noted in the values of SIF [33].

The SIF of a plate of finite width and height cracked edge is given by:

$$
K_{I}=\sigma \sqrt{2 \pi} F_{1}\left(\frac{a}{w}, \frac{h}{w}\right)
$$

with $F_{1}\left(\frac{a}{w}, \frac{h}{w}\right)$ is the normalized function which depends on the geometry of the specimen [28]. 


\subsection{Loading and Boundary Conditions}

Fully finite edge-cracked plates specimen with key dimensions as shown in Fig. 2a. A plane strain state was assumed. The width and the thickness of all samples were maintained at $\mathrm{W}=150 \mathrm{~mm}$, and $\mathrm{t}=6 \mathrm{~mm}$ respectively, while the length of the crack and the height $\mathrm{h}$ of the sample were changed. For the simulation, the values of a/ $\mathrm{W}$ were 0.3 and 0.5 , and the ratio $\mathrm{h} / \mathrm{W}$ is varied from 0.2 to 1.1 with a step of 0.1 . The load is pointed and semi distributed uniform as shown in (Figure2.b).

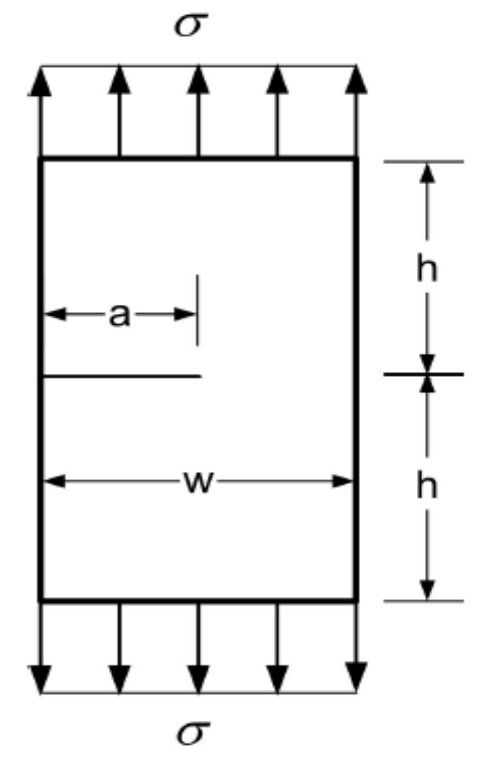

(a)

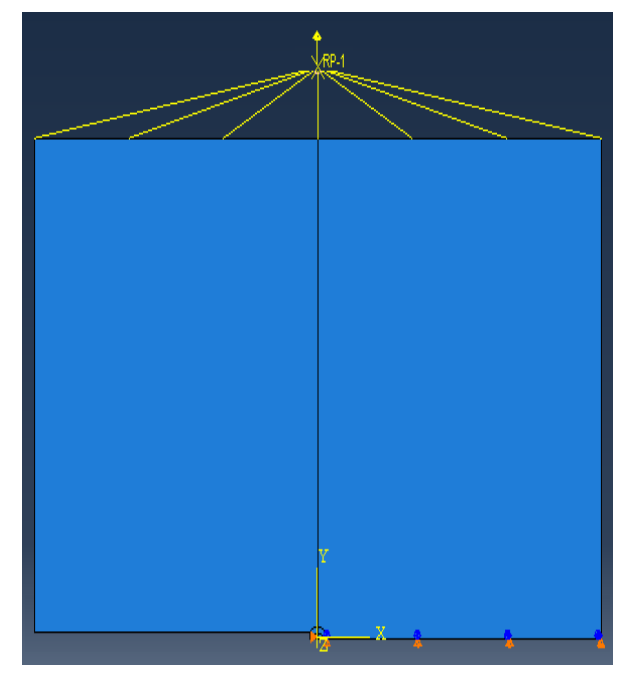

(b)

Figure 2. Centrally notched rectangular specimen under uniaxial tension: a) Geometry of the specimen; b) Load and boundary conditions of half specimen

\section{Results and Discussion}

A finite element analysis using ABAQUS 6.11.1 [33] was conducted. The extrapolation method of integral $\mathrm{J}$ was used to calculate standardized SIF mode I opening [32]. We notice that this method is consistent and profitable for a very specific SIF. Corresponding to the singular element the value of 0.25 was used in the finite element modeling [23].

From the linear equation presented in the literature, the deformations (measured) were calculated by the proposed model for different loads. Thereafter, SIF values were determined by finite element method (Abaqus).

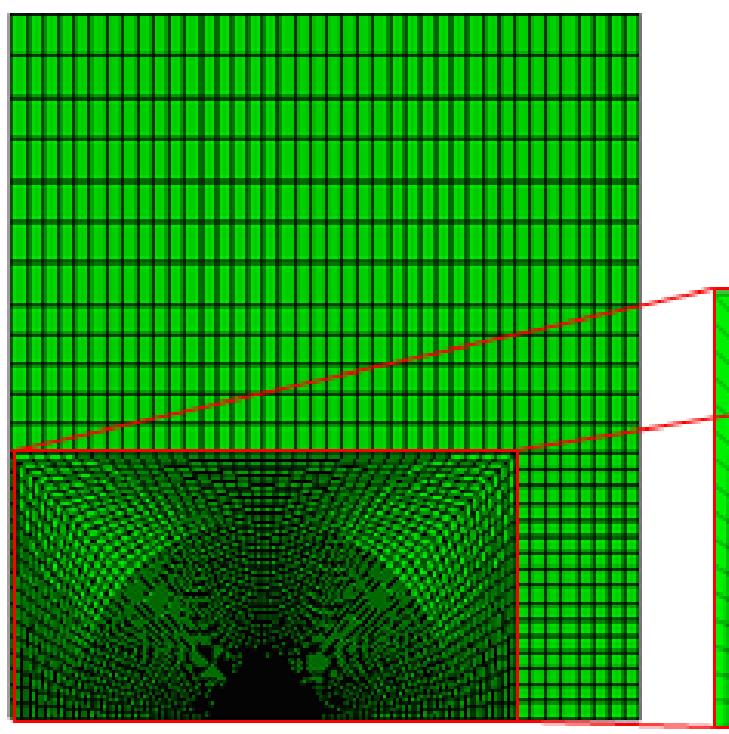

(a)

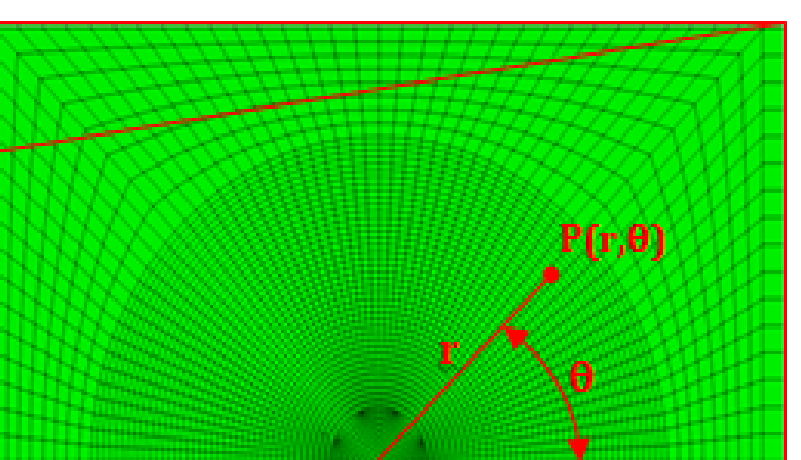

(b)

Figure 3. Illustration of : (a) Typical mesh used for the SENT (b) Detail of the refined mesh near the crack tip. 
The angles $\theta$ and $\alpha$ in equation (4) and (5) are equal $58.69^{\circ}$ and $54.76^{\circ}$ respectively. The radial position of the strain gage $\mathrm{r}$ $=3 \mathrm{~mm}$ was chosen in all tests based on the stress gradient analysis presented in [12].

Figure 4 and 5 show a comparison between the results of SIF as a function of the applied load measured experimentally [9] and obtained by the proposed model for $\mathrm{a} / \mathrm{w}=0.3$ and $0.5 \mathrm{with} \mathrm{h} / \mathrm{w}=0.3,0.5,0.7,1.0$. The figures show that the measured SIF are linearly proportional with the applied load.

A linear variation can be noted between the applied load and the SIF in all figures for the eight samples.

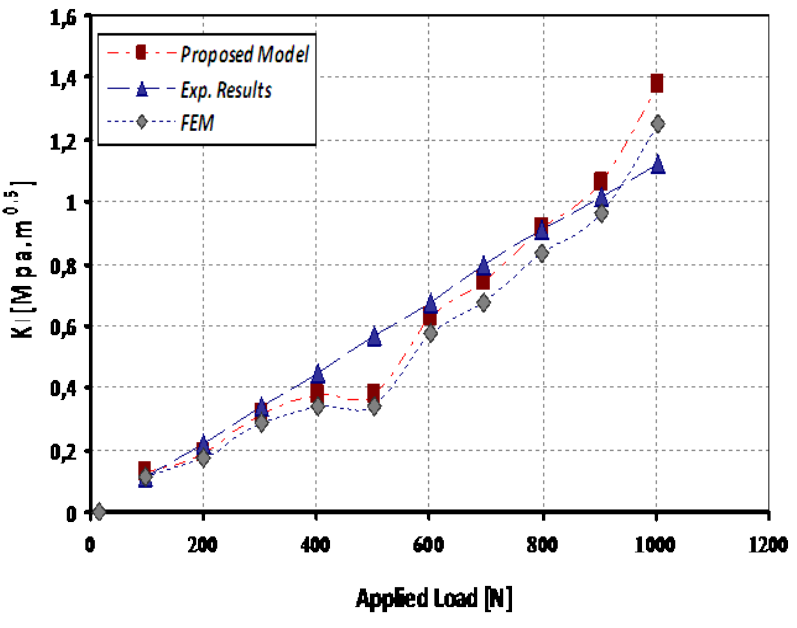

(a) $\mathrm{h} / \mathrm{w}=0.3$

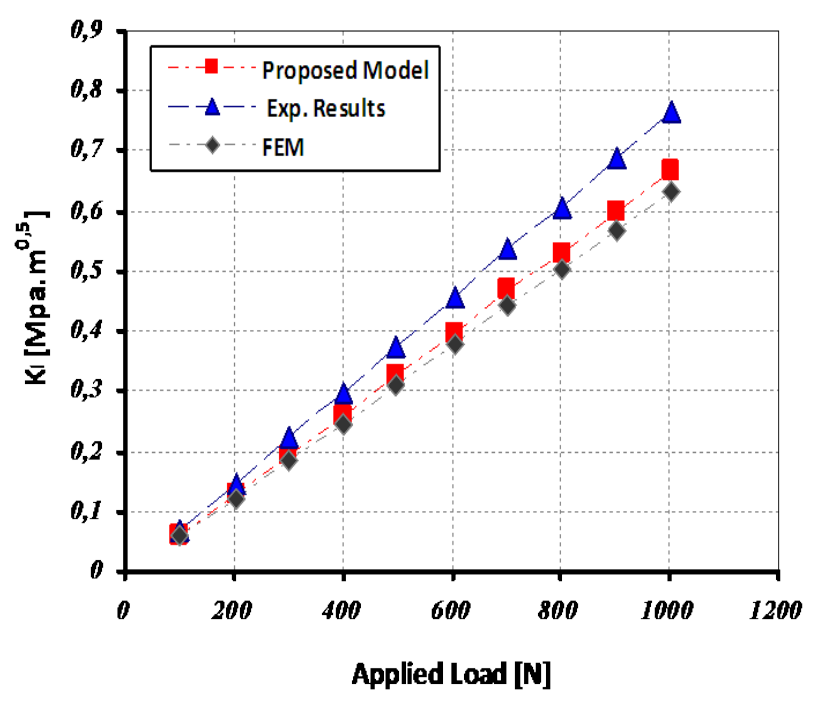

(c) $\mathrm{h} / \mathrm{w}=0.7$

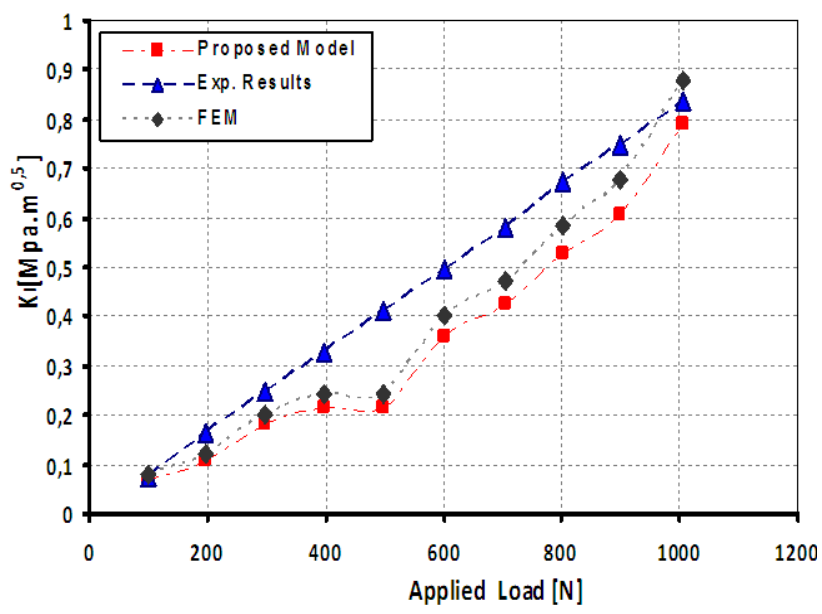

(b) $\mathrm{h} / \mathrm{w}=0.5$

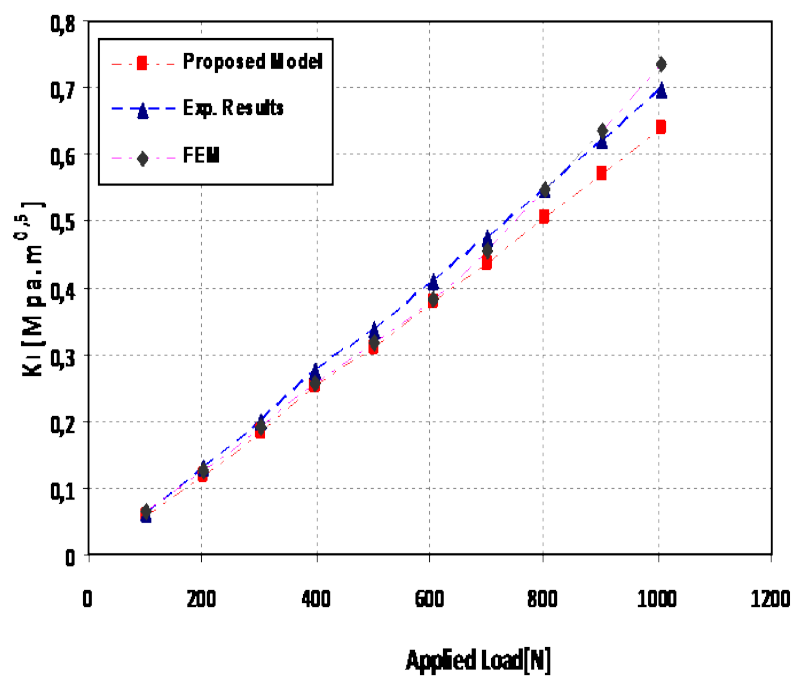

(d) $\mathrm{h} / \mathrm{w}=1.0$

Figure 4. A comparison between the numerical and experimental values of $\mathrm{SIF}$ for different values of $\mathrm{h} / \mathrm{w}$ when $\mathrm{a} / \mathrm{w}=0.3$. 


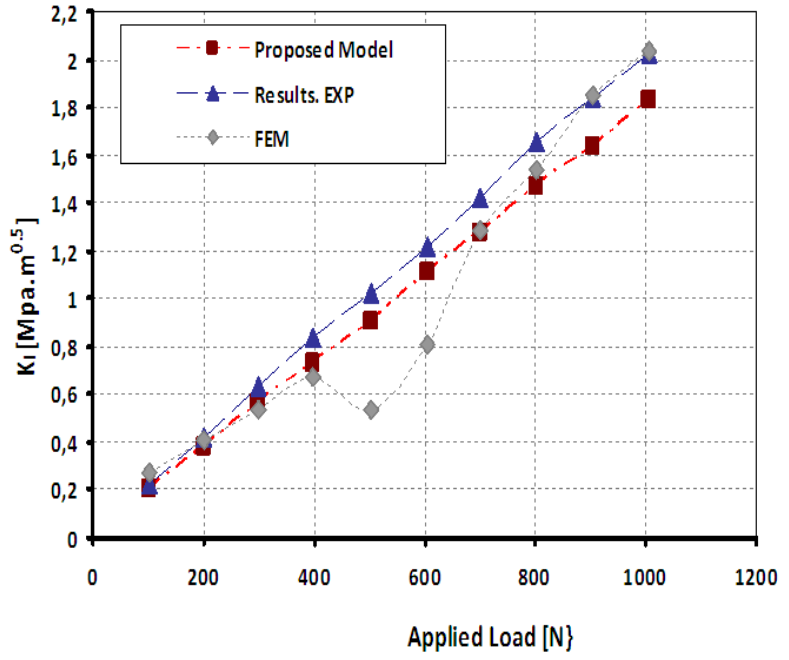

(a) $\mathrm{h} / \mathrm{w}=0.3$

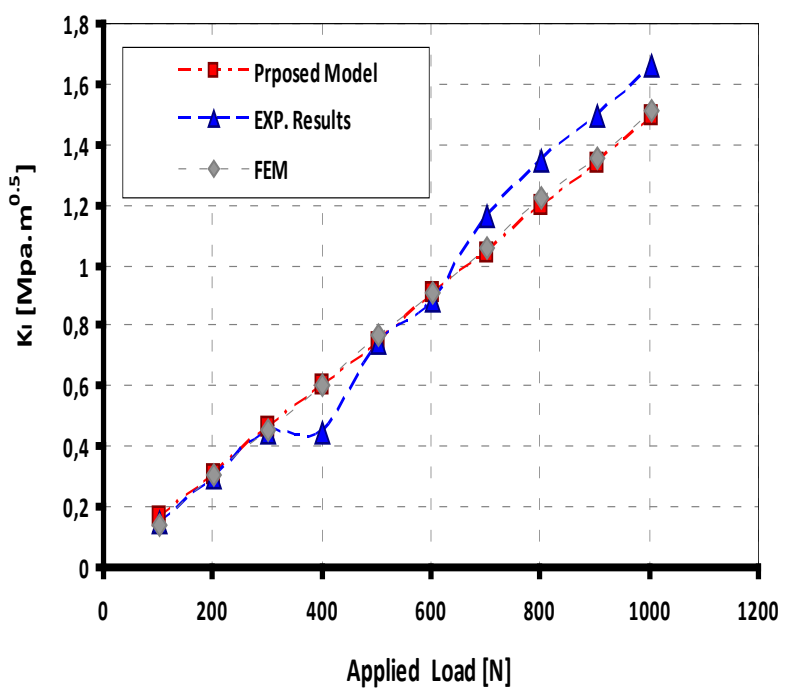

(c) $\mathrm{h} / \mathrm{w}=0.7$

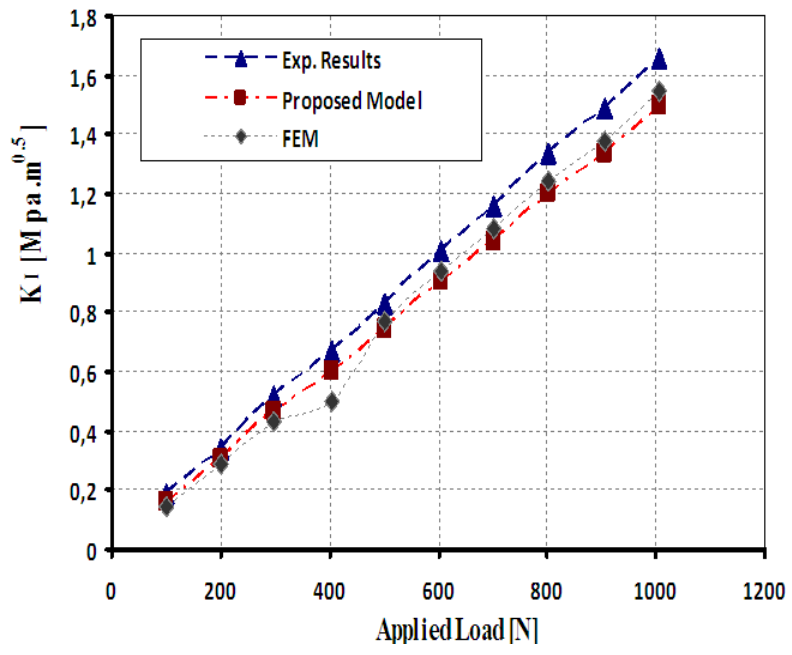

(b) $\mathrm{h} / \mathrm{w}=0.5$

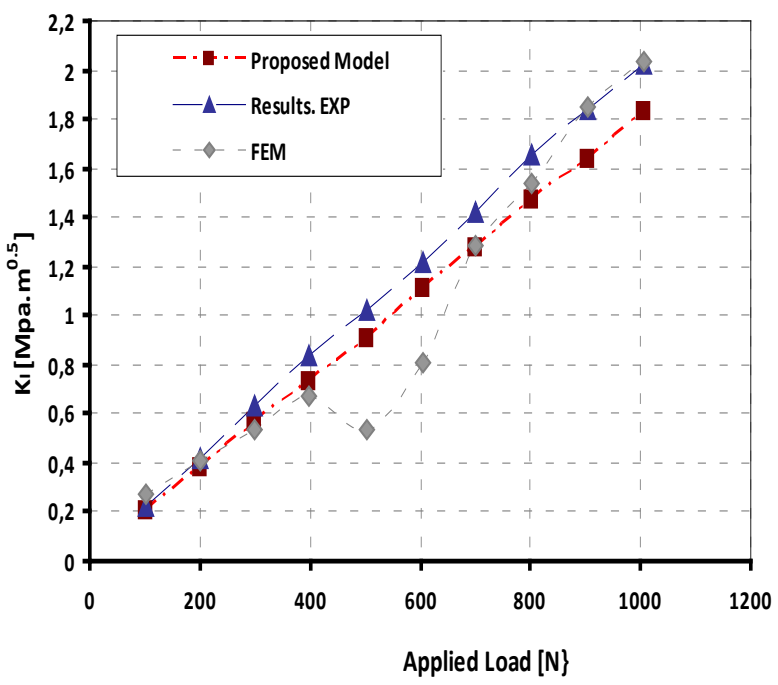

(d) $\mathrm{h} / \mathrm{w}=1.0$

Figure 5. A comparison between the numerical and experimental values of SIF for different values of $\mathrm{h} / \mathrm{w}$ when $\mathrm{a} / \mathrm{w}=0.5$.

\section{Conclusions}

In this paper, a numerical evaluation of the fracture parameters, such as, SIF parameter using the virtual strain difference method under variable loading was proposed. One type of specimen (SENT) has been examined to highlight the effectiveness and the applicability of the proposed method.

A good agreement has been found between the SIF values calculated based on this approach, and those obtained experimentally by Swamy et al [9]. That said, the proposed approach represents an alternative tool in the sense of quantitative and qualitative effectiveness for the accurate measurement of SIF in a polymer plate with finite dimensions.

The results obtained in this study show that the use of a single strain gage in "Dally Sanford's technical" is very effective in the case of PMMA.

The major interest of this technique is its ability to approaching the problem in more complex configurations.
A continuation of this work suggests a coupling between the T-Stress and $K_{I}$, with more complicated loading. An extension will be proposed for different geometries, and of course, a validation on polymeric materials other than PMMA will be considered in order to make a conclusion on the generalization of the proposed approach.

\section{REFERENCES}

[1] G. R. Irwin, "Analysis of stresses and strains near the end of a crack traversing a plate”. J. appl. Mech., Vol. 24, pp.361-364, 1957

[2] J. W. Dally, R. J. Sanford, "Strain gage methods for measuring the opening mode stress intensity factor Kt". Exp. Mech., Vol. 27, pp.381-388, 1987

[3] J. W. Dally, R. J. Sanford, "Measuring the Stress Intensity Factor for Propagating Cracks with Strain Gages", J. Test. 
Eval.,Vol. 18 No. 4, pp. 240-249, 1990

[4] J. R. Berger, J. W. Dally, “An overdeterministic approach for measuring $\mathrm{K} \sim$ using strain gages". Exp. Mech., Vol. 28, pp.142-145, 1988

[5] J. W. Dally, W. F. Riley, "Experimental Stress Analysis", pp. 410-411, McGraw-Hill, New York, 1965

[6] R. J. Sanford, "Principles of Fracture Mechanics", Prentice-Hall, Englewood Cliffs., NJ, 2002

[7] R. J. Sanford , "Sanford, Principles of fracture mechanics", Prentice Hall, Upper Saddle River, NJ, 2003

[8] R. J. Sanford "A critical re-examination of the Westergaard method for solving opening-mode crack problems". Mech. Res. Commun, Vol. 6, pp. 289-94, 1979

[9] S. Swamy, M. V. Srikanth, K. S. R. K. Murthy, P. S. Robi : "determination of mode Istress intensity factors of complex configurations using strain gages" J. Mech. Mat. Stru., Vol. 3, No. 7, 2008

[10] M. J. Malesky, M. S. KI rugulige, H.V. Tippur "A Method for Measuring Mode I Crack Tip Constraint Under Static and Dynamic Loading Conditions" Soc. Exp. Mech., Vol. 44, No. 5, pp. 522-32, 2004

[11] Y. Z. Itoh, T. Murakami and H. Kashiwaya, "Experimental determination technique of stress intensity factor and its application”. J. Engng Mater. Technol., Vol. 111, pp. 81-86, 1988

[12] A. Shukla, R. Chona and R. K. Agarwal, "Investigation of dynamic fracture using strain gage". Proc. SEM Spring Conf. Houston, TX 1987

[13] N. Levy, P. V. Marcal, J. R. Rice, "Progress in three-dimensional elastic-plastic stress analysis for fracture mechanics”, Nucl. Engng. Design., Vol. 17, pp. 64-75, 1971

[14] T. Nakamura, D. M. Parks, "Three dimensional stress field near the crack front of a thin elastic plate". J. appl. Mech., Vol. 55, pp. 805-813, 1988

[15] A. J. Rosaki s and K. Ravi-Chandar, "On crack-tip stress state: an experimental evaluation of three-dimensional effect". Int. J. Solids Vol. 22, pp.121-134, 1986

[16] M. L. Williams, "On the stress distribution at the base of a stationary crack”. J. appl. Mech., Vol. 24, pp. 109-114, 1957

[17] J. Wei, J. H. Zhao, "A two-strain-gage technique for determining mode I stress-intensity factor", Theor. Appl. Fract. Mech., Vol. 28, pp 135-140, 1997

[18] J. H. Kuang, L. S. Chen, “A single strain gage method for measurement", Engng. Fract. Mech., Vol. 51, pp871-878, 1995

[19] R. Chona, G. R.Irwin, R. J. Sanford, "Influence of Specimen Size and Shape on the Singularity-dominated Zone," Fracture Mechanics 14th Symposium, Vol. 1: Theory and Analysis, ASTM-STP, Vol. 791, American Society for Testing and Materials, Philadelphia, PA, 492-502, 1983

[20] H. V. Tippur, S. Krishnaswamy, A. J. Rosaki s, "Optical Mapping of Crack Tip Deformations Using the Methods of Transmission and Reflection Coherent Gradient Sensing: A Study of Crack Tip K-dominance,” Int. J. Fract, Vol. 52, pp. 91-117, 1991

[21] S. Swamy, M. V. Srikanth, K. S. R. K. Murthy,P. S. Robi,
"Determination of strain gage locations for accurate measurement of the opening mode stress intensity factors", J. Mech. Mat. Struc, Vol. 3, No. 7, pp. 1757-1771 , 2008

[22] P.V. Jogdand, K.S.R.K. Murthy, "A finite element based interior collocation method for the computation of stress intensity factors and T-stresses", Engng. Fract. Mech. Vol. 77, pp.1116-1127, 2010

[23] L. Parnas, O. G. Bilir, "Strain gage methods for measurement of opening mode stress intensity factor", Engng. Fract. Mech., Vol. 55, pp. 485-492, 1996

[24] T. Fett, G. Rizzi, "Weight functions for stress intensity factors and T-stress for oblique cracks in a half-space". Int J Fract, Vol.132:L9-L16. 2005

[25] C. H. Chen, C. L.Wang, "Stress intensity factors and T-stresses for offset double edge-cracked plates under mixed-mode loadings", Int. J. Fract.,Vol. 152, pp. 149-62, 2008

[26] T. Fett, "Stress intensity factors and T-stress for internally cracked circular disks under various boundary conditions" Engng. Fract. Mech., Vol. 68, pp. 1119-36, 2001

[27] T. Fett, "T-stresses in rectangular plates and circular disks". Engng. Fract. Mech., Vol. 60, pp. 631-52, 1998

[28] K. S. R. K. Murthy, M. Mukhopadhyay, "Unification of stress intensity factor (SIF) extraction methods with an h-adaptive finite element scheme". Commun. Numer. Methods. Engng., Vol. 17, pp. 509-520, 2001

[29] L. Banks-Sills, D. Sherman, "Comparison of methods for calculating stress intensity factors with quarter-point elements”, Int. J. Fract., Vol. 32, No. 2, pp. 127-140. 1986

[30] N. K. Mukhopadhyay, S.K. Maiti, A. Kakodkar "A review of SIF evaluation and modeling of singularities in BEM". Comput. Mech., Vol. 25, pp. 358-75, 2000

[31] Y. Murakami, Stress intensity factors handbook, England: Pergamon, 1987

[32] H. Tada, P.C. Paris, G. R. Irwin, The stress analysis of cracks handbook, New York, ASME, 2000

[33] ABAQUS, Theory reference manual, Release 11. Swanson Analysis Systems, Inc, 2009

[34] P.V. Jogdand, "An investigation on overdeterministic approaches for determination of the mixed mode stress intensity factors and T-stresses". Masters Thesis, Indian Institute of Technology Guwahati, India， 2009

[35] M. Isida "Effect of width and length on stress intensity factors of internally cracked plates under various boundary conditions”. Engng. Fract. Mech., Vol . 7, pp. 301-16, 1971

[36] J. P. Benthem, W. T. Koiter, "Asymptotic approximations to crack problems", in Mechanics of Fracture I, Noordhoff Leyden, 1973

[37] W. K. Wilson, "On combined mode fracture mechanics". Research report 69-1E7-FMECH-R1. Pittsburgh: Westinghouse Research Laboratories, 1969

[38] H. Ki tagawa, R. Yuuki "Analysis of arbitrarily shaped crack in a finite plate using conformal mapping, 1st reportconstruction of analysis procedure and its applicability", Trans. Jpn. Soc. Mech. Engng., Vol. 43, pp. 4354-4362, 1977 